\title{
Staged Resection
}

National Cancer Institute

\section{Source}

National Cancer Institute. Staged Resection. NCI Thesaurus. Code C155990.

A surgical procedure for the removal a tumor or multiple tumors during multiple operative procedures. 